\title{
Application and Expressiveness of Corrugated Paper in Fiber Art Perspective
}

\author{
Gongwei Li \\ Shenzhen Polytechnic \\ Shenzhen, China \\ ligongwei@ szpt.edu.cn
}

\author{
Ying Ying \\ yying@szpt.edu.cn
}

\begin{abstract}
This paper aims to analyze the art expressiveness of corrugated paper as a type of fiber art material. It explains the possibility and real achievements of this industry-usage material in the art creation domain. From the perspective of fiber art aesthetic, the beauty of colour and texture of corrugated paper art are comprehensively studied. The paper at last gives advices on future development breakthrough and possible techniques to be deployed.
\end{abstract}

Keywords-corrugated paper; fiber art; colour; texture

I. The Possibility of Corrugated Paper Used as AN ART CREATION MATERIAL

In addition to its application as a packaging material, corrugated paper has drawn artists' attention by its unique physical property and becomes a new material for art expression. Examples include the decoration work and posters by Mark Langan, furniture works by Frank Gehry and sculpture works by Chris Gilmour. All of them are created by exploiting the fiber property of corrugated paper and its bumpiness.

Among the wide creation spectrum of corrugated paper art, there is one design theme that specializing in applying and demonstrating the fiber aesthetic feature of the material. The raw material of corrugated paper include kraft pulp and semichemical pulp. Both of them come from plant fiber. Thus, naturally, corrugated paper bears the the properties of fiber material. This becomes the precondition and advantage of its application in fiber art creation.

\section{Aesthetic Analysis of Fiber ART}

The charm of fiber art lies in the contrast relationship between different things or different parts. Such as strong vs. soft, straight vs. curved, bright vs. dark, and light vs. heavy. Those contrasts arouse varied emotions and bring up rich aesthetic feelings. Fiber art materials, in the way as they are, are full of all sorts of contrast. Artists deeply study them, and demonstrate them with clever and skillful manners to create successful fiber art works.

To analyze the beauty of fiber art, there are two perspectives----colour and texture.

Colour of no doubt, is the most direct way to receive visual stimulation. In the modern fiber art environment, artists emphasis on the natural and unique colour of materials itself.
One of the most used manners to express colour is increasing the colour contrast while decreasing the texture contrast. One category of works use nearby colours, lots of uneven texture and abstract shapes, to express the delicate colour changes that are embodied in texture compilation. Another category of works focus on contrasting materials and colours, applying full effects of contrast between colour patches, line and surface, and dot and line, to achieve exquisite and rich colour effect.

Texture, to a certain degree, is the core content of fiber material' s expressiveness. Various aesthetic perceptions are presented by the various shapes, sizes, thicknesses and other qualities of the materials. Each type of material earns its unique beauty by its textural tension of physical tendency. This brings infinite possibilities for art creation.

The interaction between colour and texture needs to be concerned as well. On one side, colour is an important element for presenting texture. Texture loses its charm without the help of colour. On the other side, materials that are not perfect in colour presentation can be retrieved with techniques and have their texture altered, so that their original colour and pattern can be better presented. In the modern technology environment, more and more new techniques and new materials are generated for artists to deploy in fiber art creation. And thus, new skills, new crafts and new styles come up.

\section{The COLOUR EXPRESSIVENESS OF CORRUGATED PAPER FIBER ART}

\section{A. Original colour}

The original colour of corrugated paper is close to earth yellow. It gives a primitive and simple tone that make people feel intimate and at ease. The decoration wall presented in Fig.1 is made with waste board paper. The work is designed in a simple structure, with little use of technique and processing, exposing large area of the original colour. The minimalism design is a perfect match to the raw beauty of the material itself . The work, indulging the original colour to show up vastly, brings a leisure and warm atmosphere to the room space. 


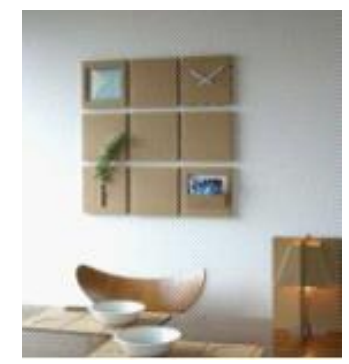

FIGURE I. DECORATIVE WALL MADE WITH BOARD PAPER

\section{B. Contrasting colours}

Contrasting colours, means the to contrast multiple colours in space or time relations so that their differences can be highlighted. The major manners to contrast colours include hue contrast, lightness contrast, saturation contrast, tone contrast, and area contrast. There are multiple flute structures of corrugated paper. When mixed and matched together, or use only one flute type but arranged in various directions, interesting colour changes occur. The work of Fig. 2 has used merely one type of flute structure material but with crisscrossing array. Light reflects in various directions when hit on paper edge so that contrast between bright and dark shows up.

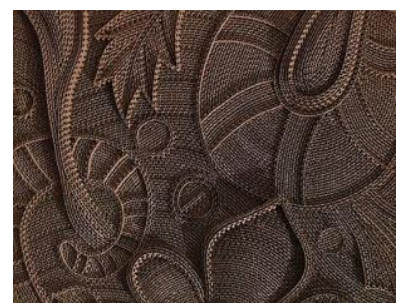

FIGURE II. CRISSCROSSING ARRANGEMENT OF ONE FLUTE TYPE PAPER

\section{Synthesizing colours}

It mainly lies on by synthesizing craft paper and corrugated paper. For example, Fig.3 is a work by Mark Langan. Different types of flute structures were artfully arranged to make up patterns and tint changes. The coloured craft paper and rubbed craft paper make obvious contrast with the corrugated paper edge, manifesting the smoothness of craft paper and the coarseness of corrugated paper edge. A diversity of materials and arrangements, with the use of multiple skills, has made the work delicate and plentiful.

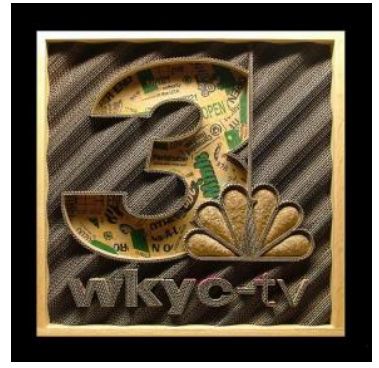

FIGURE III

A CORRUGATED PAPER ART WORK BY MARK LANGAN

\section{ThE TEXTURE EXPRESSIVENESS OF CORRUGATED PAPER FIBER ART}

\section{A. Natural texture}

Corrugated paper is formed by materials of several sorts of structure. A piece of corrugated paper can be dismantled into multiple parts of different structures: the corrugated paper edge, corrugated paper board and craft paper. Each of them has unique physical attributes and presents individual visual and tactile effect, which might be bumpy, rough, smooth, soft, or hard.

\section{1) Texture of plane construction}

A good use of texture to an art work, adds flavor and novelty, breaks down monotonousness, improves delicacy, and arouses more reflections and contemplation for viewers. The work of Fig.4 uses splicing and dislocating techniques to organize various types of corrugated structures, presenting a plumpy picture. The work of Fig.5 is created by Taiwan artist Pei-ying Huang. Corrugated-paper-made petals and craftpaper-made kernels are skillfully constructed together to make dramatic contrast between smoothness and coarseness. Receiving light from top of side, the work even becomes more cubic and gives a shallow relief effect.

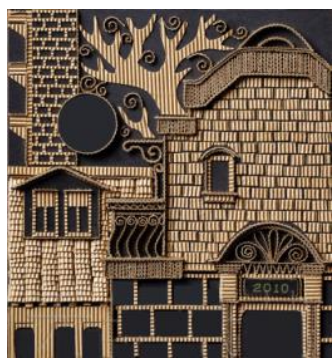

FIGURE IV.

A CORRUGATED PAPER ART WORK

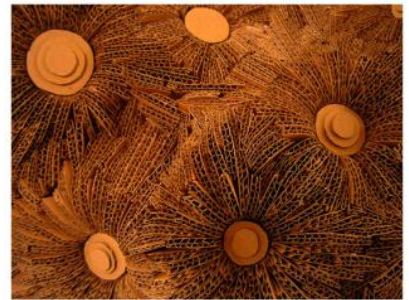

FIGURE V. A CORRUGATED PAPER ART WORK BY PEI-YING HUANG

\section{2) Texture of cubic construction}

Same as shape and colour, texture of cubic construction is one of the form languages that have style and emotion effect. Texture presents a unique beauty in certain space, light, or environment. Corrugated paper's flexibility and solidity have been deployed by artists to construct cubic art works, with interweaving, splicing, assembling and other techniques. In this way, form beauty of repetition, gradual transformation, contrast and balance is demonstrated and texture sense of cubic construction shows up. Just as how the work of Fig.6 illustrates. 


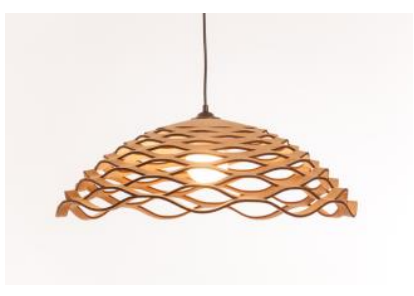

FIGURE VI.

A CEILING LAMP MADE WITH CORRUGATED PAPER

\section{B. Skill-processed texture}

Each material has its unique physical surface, which gives viewers a corresponding perception of texture. Modern technology has developed new techniques and skills that can be used to change original raw materials and even generate new materials. Thus new formation of texture comes into being and add to art creation possibility. Such techniques and skills include fuzzing, burning, bending, cutting, rubbing, scraping, grinding and etc. For example, the work of Fig.7 is an adaptation of Edvard Munch's Scream. The head of the screaming figure and the background are made with rubbed and fuzzed craft paper. And Fig.8 is a loudspeaker case by Sruli Recht. The work is constructed from corrugated cardboard and then appears to be either burned or painted in a process that looks to be applied by hand.

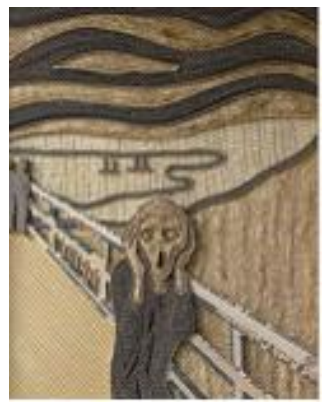

FIGURE VII.
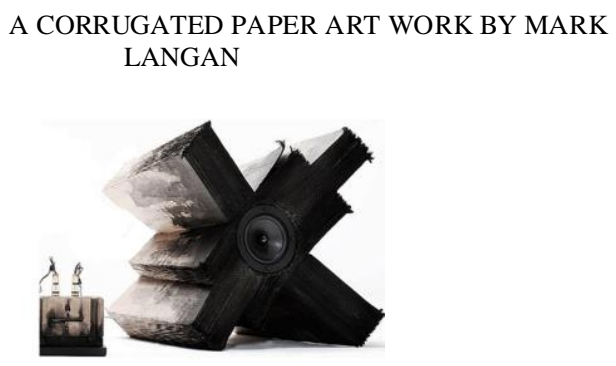

FIGURE VIII

$$
\begin{aligned}
& \text { A LOUDSPEAKER CASE MADE WITH } \\
& \text { CORRUGATED PAPER }
\end{aligned}
$$

\section{MORE IDEAS ON FURTHER DEVELOPMENT}

The cheap and easy-access attributes of corrugated paper make it fully deployed in art creation field. However, it is also because of these that prohibits corrugated paper into high-end art domain. Therefore, artists need to think higher in aesthetic levels and think deeper in themes and seek more delicacy and novelty in technique. So that to lift corrugated paper fiber art to a lever higher than ordinary decoration.

So far, there have been lots of attempts on applying new skills to create corrugated paper art work. But works that presented with light and shadow effect are seldom seen. The original colour tones of corrugated paper have a tendency to be dull and mild, and give limited visual attraction. Lighting (both natural and artificial) can be used to generate contrast between figures and their shadows, and contrast between bright and dark.

\section{ACKNOWLEDGMENT}

This paper is one of the stage research results of the 2011 Shenzhen Polytechnic humanities and social sciences research project "Environmental protection and art: the expressiveness of corrugated paper in formative arts".

\section{REFERENCES}

[1] Z. Li, T. Xiong, and H. Meng, "Application research of corrugated paper's production in life," Furniture \& Interior Design, vol. 9, pp. 56-57, 2010.

[2] Z. Wang, and X. Zhang. "Decorativeness of fiber art," Art and Design, vol. 6, pp. 270, 2010.

[3] Z. Gao, "Texture and art demonstration," Art Observation, vol. 3, pp. $115,2012$.

[4] H. Tan, "The spacial property of modern fiber art," Writer Magazine, vol. 6, pp. 243-244, 2013 